\title{
Laviosa, Sara. Translation and Language Education: Pedagogical Approaches Explored, New York and London: Routledge, 2014, 174 p.
}

Socorro Gardênia Carvalho de Paula ${ }^{1}$ ${ }^{1}$ Universidade Federal do Ceará, Fortaleza, Ceará, Brasil

O livro "Translation and Language Education: Pedagogical Approaches Explored", de Sara Laviosa, trata de fazer uma exposição sobre a relação entre os Estudos da Tradução e o ensino e aprendizagem de línguas estrangeiras, propondo uma pedagogia holística onde a tradução e o ensino de línguas coexistem e dialogam de forma positiva no mesmo ambiente de aprendizagem. A autora é professora de Língua Inglesa e Tradução na Universidade de Bari “Aldo Moro", na Itália. Ela é mestra em Inglês como Segunda Língua/Língua Estrangeira pela Universidade de Birmingham, Reino Unido e tem doutorado em Estudos da Tradução pela Universidade de Manchester, Reino Unido.

A obra possui nove capítulos e um apêndice, contendo os questionários usados pela autora durante sua pesquisa e alguns dos materiais empregados durante as sessões de ensino. No primeiro capítulo é feita uma descrição histórica do papel da tradução no ensino de segunda língua em diferentes métodos e abordagens, iniciando com o tradicional Método da Gramática e Tradução que se fez dominante nas escolas europeias de 1840 à 1940, passando por diferentes abordagens do movimento da pré-reforma e reforma, dando prosseguimento com a descrição do Método Direto, o 
Método Oral, Método Situacional, Ensino Estrutural de Línguas, Método Audiolingual, até o surgimento do Método Comunicativo no final da década de 1960. A autora discorre sobre os propósitos e contextos educacionais de cada um dos métodos, dando enfoque à presença ou não da tradução como instrumento no auxílio do ensino de línguas estrangeiras.

O segundo capítulo inicia com foco no desenvolvimento das principais considerações teóricas em favor do uso de diversas formas de tradução no ensino de línguas estrangeiras. Para Duff (1989), por exemplo, aprender a traduzir uma ampla gama de tipos de textos, registros e estilos, tanto na linguagem escrita quanto na falada, aprimora uma variedade de habilidades essenciais para a aquisição da segunda língua e no ambiente de trabalho multilíngue. Desta forma, Duff, defende a readmissão da tradução na sala de aula de línguas, tanto como um meio eficaz de alcançar a proficiência linguística quanto como uma habilidade em si mesma, alcançando o mesmo valor de outras técnicas como literatura, conversação e dramatização. Postura similar é a de Penelope Sewell e Ian Higgins em "Teaching Translation in Universities" (1996a), que consiste em artigos sobre a tradução como um dispositivo de ensino de L2 e como um fim em si mesmo. Portanto, o que se percebe através dessas e outras considerações feitas ao longo do capítulo é que elas possuem foco na legitimação da tradução como meio adicional de ensinar e testar a proficiência em segunda língua e como habilidade em si mesma. Logo em seguida, o capítulo tem sua continuidade com a análise de vários estudos experimentais e de pesquisa acerca das considerações teóricas que proclamam a eficácia da tradução como meio de avaliação de proficiência de segunda língua e como ferramenta de ensino. Como resultado, tais análises demonstram a confirmação de muitas das considerações feitas a cerca do renascimento da tradução como parte do ensino de línguas. Por fim, o capítulo trata da descrição de propostas pedagógicas que se utilizam do processo da bilingualização, em que os estudantes recorrem à língua que conhecem como recurso para acessar a língua que não conhecem (Widdowson 159). 
No terceiro capítulo, Sara Laviosa discute o que ela chama de "abordagens ecológicas", que pressupõem a aprendizagem como uma atividade humana relacional não linear, co-construída entre humanos e seu ambiente, dependente de sua posição no espaço e na história e um local de luta pelo controle do poder social e memória cultural (Kramsch 5). Desta forma, "seu estudo ecológico se concentra no modo como os indivíduos se relacionam com o mundo e entre si por meio de sistemas linguísticos e de outros signos" (van Lier 147). Portanto, trata-se de um ambiente de aprendizagem colaborativa, onde a utilização da língua materna é vista como essencial para o alcance da proficiência em segunda língua. Metaforicamente, o capítulo faz a descrição da linguagem como um ecossistema onde seus co-participantes estão interligados, bem como discute a relação de simbiose entre língua e cultura.

No quarto capítulo encontra-se uma exemplificação de pedagogia baseada nos preceitos das abordagens ecológicas descritas no capítulo anterior. Trata-se da abordagem multilíngue de ensino e aprendizagem de língua estrangeira no ensino superior, promovida por Claire Kramsch. Tal abordagem se baseia no "eu" simbólico, que não é nato, mas construído através de diálogos com o ambiente, através das interações sociais, entendido como uma unidade de sentimentos, emoções, pensamentos e consciência corporal. Os diálogos são simbólicos, visto que o "eu" se põe no lugar do outro, imagina suas respostas e como é visto pelo outro, tentando adequar suas respostas às expectativas do outro. Desta forma, o "eu" simbólico é descrito como holístico, social e auto-reflexivo. O capítulo aborda a necessidade de se desenvolver o "eu" simbólico para o processo de se tornar um sujeito multilíngue. Descreve também a competência comunicativa intercultural e seu objetivo de formar falantes interculturais, que sejam capazes de ver similaridades e diferenças entre línguas e culturas e agir como mediadores entre as pessoas envolvidas. No capítulo, a autora levanta a bandeira da importância do envolvimento com o outro tanto cognitivamente como emocionalmente na aprendizagem de línguas. 
A abordagem holística empregada para a tradução das diferenças culturais, de Maria Tymoczko, é o assunto discutido no quinto capítulo. Para que se tenha um melhor entendimento do assunto, a autora discute as noções de tradução como representação, transmissão e transculturação como sendo modos de intercâmbio cultural que se relacionam entre si, e que são úteis para investigar traduções dentro de uma perspectiva internacional e transcultural. Desta forma, traduzir cultura envolve representar, transmitir e transculturar não apenas elementos culturais materiais, mas também signos, símbolos, códigos, crenças, valores, ideias, ideais e ideologias (Tymoczko 226). A seguir, a autora analisa os fundamentos teóricos da noção de tradução cultural holística, explorando como os tradutores podem se engajar na tarefa de tradução da cultura e afirmando, por exemplo, a importância de eles serem capazes de interpretar as práticas e disposições culturais incorporadas e situadas da sua própria cultura e da cultura da audiência receptora (Tymoczko 230). Sendo assim, a autora explicita a importância da abordagem holística e reitera que tal abordagem abrange a tradução de elementos menos tangíveis, e envolve considerar os fundamentos culturais do texto-fonte que precisam ser negociados por apresentarem dificuldades para o público-alvo, de modo a permitir maior intercâmbio e uma afirmação cultural mais eficaz na tradução. A autora finaliza o capítulo demonstrando como uma abordagem holística da tradução pode ser utilizada de forma pedagógica, ressaltando atividades em que o tradutor tome consciência de seu papel como criador de significados, e explicitando a importância de se ter um ambiente de aprendizado onde o ensino de idiomas e tradução caminhem juntos de forma multualmente enriquecedora de prática transcultural.

O sexto capítulo parte de uma análise dos pontos em comum entre a tradução holística de Tymoczko e a competência simbólica de Kramsch, mostrando que ambos estão interligados tanto na teoria como na prática. Assim, afirma a possibilidade de trabalhar com ambos princípios para que se possa desenvolver uma boa prática pedagógica que se faça essencial para o profissional de línguas 
do futuro. Em seguida, o capítulo trata de mostrar evidências empíricas a respeito da convergência entre competência simbólica e tradução holística, descrevendo a experiência da autora e tradutora Isabella Vaj que compartilha suas percepções a respeito de aprendizagem de línguas, tradução literária e escrita criativa advindas de sua prática pedagógica. Finalizando o capítulo, a autora utiliza-se dos pressupostos advindos da teoria e prática descritas no decorrer do capítulo para propor uma pedagogia holística que una em um mesmo ambiente de aprendizagem a perspectiva ecológica adotada por Kramsch na educação em língua estrangeira e a abordagem holística para a tradução cultural nos estudos da tradução, adotada por Tymoczko.

Nos capítulos sétimo e oitavo, a autora apresenta atividades concretas que exemplificam a pedagogia proposta no capítulo anterior. $\mathrm{O}$ sétimo capítulo traz duas atividades que foram feitas com estudantes de italiano de nível intermediário e pré-intermediário em uma universidade americana. A tarefa propunha a tradução de um texto verbal do italiano para o inglês, a língua materna. $\mathrm{O}$ oitavo capítulo traz um exemplo de atividade feita com estudantes de inglês de pósgraduação em uma universidade da Itália. O grupo teve que traduzir um texto verbal do inglês para sua língua materna, o italiano. Em todas as atividades o objetivo era explorar a criação de significados através da interação de diferentes formas de comunicação (músicas, imagens e tradução). Desta forma, cada tarefa possuía figuras e ao lado de cada uma um trecho do texto. Foi tocada uma música que de certa forma correspondia às mesmas emoções contidas no texto, e os alunos foram convidados a fazer uma reflexão e análise em grupo sobre os significados expressos pelas imagens e pela música e que emoções e mensagens simbólicas estariam presentes em ambos os textos. Em seguida, os alunos tiveram que responder a algumas questões elaboradas pelo professor como forma de guiar o entendimento das mensagens. Assim, em um debate em grupo e com o professor, e a partir das sensações provocadas pela música e pelas imagens, foram se criando os significados, captando a nature- 
za simbólica das palavras e considerando a cultura correspondente das língua alvo e de partida, ao invés de simplesmente fazer uma tradução literal. Após essa preparação, os alunos tiveram que elaborar a tradução do texto completo, na sala, individualmente, ou em casa. Em ambos os capítulos pode-se perceber como a interação entre teoria, pesquisa e prática na sala de aula colabora para o desenvolvimento da auto-reflexão e o pensamento crítico, ao mesmo tempo que impulsiona os estudantes na aprendizagem de línguas sob um viés intercultural e interdisciplinar.

O último capítulo resume algumas das pesquisas atuais sobre tradução para fins educacionais, englobando sete artigos que reafirmam a importância da utilização da tradução em sala de aula e propõem pedagogias baseadas na tradução, concebidas dentro da interdisciplinaridade.

Desde o tradicional Método da Gramática e Tradução até os dias atuais, a tradução sempre esteve, de alguma forma, presente no ensino e aprendizado de línguas estrangeiras, porém nos últimos anos percebe-se uma mudança de visão sobre o papel da tradução na sala de aula como instrumento para alcançar proficiência linguística ou como uma quinta habilidade junto ao ouvir, falar, ler e escrever. A autora reafirma a necessidade da tradução no ensino de línguas com o argumento de que há uma demanda pela formação de tradutores e intérpretes, e a tradução ser o contexto ideal para o desenvolvimento de habilidades translinguais e transculturais como um princípio organizador do currículo de línguas. A obra de Laviosa é de extrema importância na medida em que representa uma forma de incentivo para que estudiosos da tradução e educadores de línguas trabalhem juntos em prol do desenvolvimento e utilização de abordagens e métodos pedagógicos interdisciplinares. O livro explora bons exemplos de como teoria interdisciplinar, pesquisa e prática podem se desdobrar em metodologias e práticas pedagógicas engajadas na reabilitação da tradução em sala de aula dentro de uma perspectiva multilíngue. 


\section{Referências}

Duff, Alan. Translation. Oxford: Oxford University Press, 1989.

Kramsch, Claire. 'How Can We Tell the Dancer from the Dance?'. In: Kramsch, Claire. (Ed.). Language Acquisition and Language Socialization: Ecological Perspectives. London: Continuum, 2002, p. 1-30.

Laviosa, Sara. Translation and Language Education: Pedagogical Approaches Explored. New York and London: Routledge, 2014, 174 p.

Sewell, Penelope; Higgins, Ian. (Eds.). Teaching Translation in Universities: Present and Future Perspectives, London: AFLS and CILT, 1996.

Tymoczko, Maria. Enlarging Translation, Empowering Translators. Manchester: St. Jerome, 2007.

Van Lier, Leo. "An Ecological-Semiotic Perspective”. In: Kramsch, Claire. (Ed.). Language Acquisition and Language Socialization: Ecological Perspectives. London: Continuum, 2002, p. 64-140.

Widdowson, H. G. Defining Issues in English Language Teaching. Oxford: Oxford University Press, 2003.

Recebido em: 01/12/2019

Aceito em: 15/03/2020

Publicado em maio de 2020

Socorro Gardênia Carvalho de Paula. E-mail: gpaula1209@gmail.com. ORCID: https://orcid.org/0000-0001-9664-8124 